\title{
DETERMINING THE NITROGEN BALANCE OF WHEAT FERTILIZER AND POTENTIAL ENVIRONMENTAL CONSEQUENCES IN THE FIELD OF DUKAGJINI
}

\author{
Nexhdet Shala ${ }^{1}$, Arsim Elshani ${ }^{1 *}$, Ibrahim Hoxha ${ }^{1}$ \\ I*University of "Haxhi Zeka", Faculty of Agribusiness, Peja 30000, Kosovo; \\ *Corresponding author Arsim Elshan, e-mail: arsim.elshani@unhz.eu;
}

Received July 2020; Accepted August 2020; Published September 2020;

DOI: https://doi.org/10.31407/ijees10.409

\begin{abstract}
Wheat fertilization represents one of the most complex problems in mineral nutrition of this strategic crop. Therefore, the purpose of this research is to determine a nitrogen balance in wheat culture having in consideration the environmental consequences when applying fertilizers. During this study the objectives are focused on: (1) finding optimal doses for wheat fertilization as a function of its predetermined yield, (2) predicting, determining and modifying the need for nitrogen fertilization in the context of a predetermined yield through the DRIS system (Diagnostic and Recommendation Integrated System) and (3) studying the environmental effects when applying different doses and modes of nitrogen fertilizer to wheat. It is known that plants absorb nitrogen, mainly in two forms; $\mathrm{NO}_{3}$ and $\mathrm{NH}_{4}{ }^{+}$. Nitrites, in general are more concentrated that ammonia forms, and thus, they are easier to absorb from plants through mass flow and diffusion phenomena. However, plant preferences for one or the other form of nitrogen depend on the developmental phenotypes of the plant, its type, theionic environment and other factors. Grains (Cereals), corn, rice, legumes, etc. use both forms.
\end{abstract}

Key words: Ammonia Nitrogen, Atmospheric Nitrogen, Crop Production, Dose Optimization, Environmental Consequences.Mineral Nitrogen, Nitrogen nitrate, Wheat Fertilizer Balance. 